\title{
Median Duration of Hospital Stay after Early Removal of Foley's Catheter among Patients Undergoing Transurethral Resection of Prostate: A Descriptive Cross-sectional Study
}

\author{
Pashupatinath Bhatta, ${ }^{1}$ Akash Raya, ${ }^{2}$ Umesh Kumar Yadav, ${ }^{2}$ Vijay Kumar, ${ }^{2}$ Sanjeev Shahi, ${ }^{2}$ Amit Singh ${ }^{2}$ \\ 'Urology Unit, Department of Surgery, National Medical College, Birgunj, Nepal, ${ }^{2}$ Department of Surgery, National \\ Medical College, Birgunj, Nepal.
}

\section{ABSTRACT}

Introduction: Transurethral resection of the prostate requires a catheter in situ post-surgery. Early removal of a catheter can reduce the length of hospital stay reducing the healthcare cost. It can also reduce the risk of infection due to prolonged catheterization. Our aim was to determine the median duration of hospital stay after early foley's removal after transurethral resection of prostate among patients in a tertiary care hospital.

Methods: A descriptive cross-sectional study was done in a tertiary care hospital from July 2019 to December 2020 and ethical clearance was obtained from the institutional review committee. Foley's catheter were removed on the first post-operative day, who met the criteria of catheter removal. Convenience sampling was done. After foley's removal patients were observed for spontaneous voiding. Patients with complications like hematuria, clot retention, urinary retention were recatherized. The data were expressed in mean with standard deviation, median with interquartile range and frequency and percentage as applicable using Statistical Package for the Social Sciences version 16.

Results: Out of the 150 participants included in the study, the median duration of hospital stay after the early removal of foley's catheter was 3 days (interquartile range 2-4 days). A total of 20 (13.3\%) patients underwent recatherization. Nine $(6 \%)$ patients had to be recatheterized due to clot retention, and $11(7.3 \%)$ were due to urinary retention.

Conclusions: This study showed that the median duration of hospital stay after early removal of foley's catheter among patients undergoing transurethral resection of the prostate was similar to studies done in national/international settings.

Keywords: benign prostatic hyperplasia; hospital stay; transurethral resection of prostate; urinary catheter.

\section{INTRODUCTION}

Benign prostatic hyperplasia (BPH) is considered as a part of ageing process in male and is hormonally dependent on testosterone and dihydrotestosterone (DHT) production. ${ }^{1}$ There are various methods proposed for treatment of $\mathrm{BPH}$, transurethral resection of prostate (TURP) remains gold standard. ${ }^{2}$ The increasing number of patients, long waiting list for TURP and lengthy hospital stay due to post-operative foley's catheterization is considered to be discomfort and cost disadvantage. ${ }^{3}$ This can be overcome by early removal of foley's catheter after TURP when appropriate and safe. As per various studies duration of hospitalization is 2-7 days. Among the total cost of TURP, 29-33\% represent hospital stay charges. ${ }^{4}$

This study aimed to find out the median duration of hospital stay after early catheter removal on first postoperative day after TURP.

Correspondence: Dr. Pashupatinath Bhatta, National Medical College, Birguni, Nepal. Email: pashupati_bhatt@ yahoo.com, Phone: +977-9841281810. 


\section{METHODS}

A descriptive cross-sectional study was done at National Medical College Department of Surgery, Urology Unit, Birgunj from July 2019 to December 2020. Ethical clearance was taken from the Institutional Review Committee (reference number: FNMC/439/075/76). The study was done among patients who underwent TURP and had early removal of foley's catheter. Patients undergoing TURP for BPH were included in the study. Bladder carcinoma, prostatic carcinoma, renal failure, cardiovascular diseases and other condition that require fluid restriction were excluded form the study. Digital rectal examination done in all cases to rule out nodularity. Convenience sampling was done and the sample size was calculated as,

$\mathrm{n}=\mathrm{Z}^{2} \times \sigma^{2} / \mathrm{e}^{2}$

$=(1.96)^{2} \times(0.5)^{2} /(0.08)^{2}$

$=150$

Where,

$\mathrm{n}=$ minimum required sample size

$Z=1.96$ at $95 \%$ Confidence Interval $(\mathrm{Cl})$

$\sigma=$ standard deviation obtained from simiar study, $0.5^{5}$

$\mathrm{e}=$ margin of error, $8 \%$

Therefore, the required sample size was 150 and the same number of participants were included. Patient were admitted one day before surgery. Positive urine culture were treated according to culture sensitivity report. All TURP performed under spinal anesthesia by a single urologist. TURP was performed according to standard technique by using glycine $1.5 \%$. After completion of procedure prostate chips were evacuated by ellik evacuator and 22/24 3-way foley's catheter were inserted and bladder irrigation continued with normal saline, the catheter was placed on traction up to 6 hours. Age, the weight of resected prostate and re-operation, intraoperative complication, hospital stay were recorded.

The decision to remove the catheter was made by the urologist on next day at morning round. Criteria of catheter removal was normal vital sign, normal urine output, functioning irrigation channel, absence of clot, and adequate catheter effluent.

After removal of catheter patients were observed for spontaneous voiding. Recatherization was done in patients with severe hematuria, clot retention, urinary retention. Those patients who voided satisfactorily were discharged on next day with advise to follow up after one week with histopathological report.
The data was collected in data collection sheet and was entered in Microsoft Excel 2016. Data analysis was done using the Statistical Package for the Social Sciences (SPSS) version 16 . The data were expressed in median with interquartile range, mean with standard deviation, and frequency with percentage where applicable.

\section{RESULTS}

Out of the 150 paticipants of the study, the median duration of hospital stay was 3 (interquartile range 2-4) days with a minimum of two and maximum of seven days. In 130 (86.7\%) cases, early foley's cathter removal was done with a minimum two and maximum five days. In 20 (13.3\%) cases, recatherization was done in which the mean duration of hospital stay was 5 (interquartile range 4.75-6) days with minimum four and maximum seven days (Table 1 ).

\begin{tabular}{|lllll|}
\hline \multicolumn{3}{|l|}{ Table 1. Duration of Hospital Stay. } & \\
\hline Variab- & $\mathbf{n}(\%)$ & $\begin{array}{l}\text { Median } \\
\text { duration and } \\
\text { interquartile } \\
\text { range of } \\
\text { hospital stay } \\
\text { (days) }\end{array}$ & $\begin{array}{l}\text { um } \\
\text { (days) }\end{array}$ & $\begin{array}{l}\text { mum } \\
\text { (days) }\end{array}$ \\
$\begin{array}{l}\text { Hospital } \\
\text { Stay }\end{array}$ & $150(100)$ & $3(2-4)$ & 2 & 7 \\
$\begin{array}{l}\text { Without } \\
\begin{array}{l}\text { Re- } \\
\text { catherization }\end{array}\end{array}$ & $\begin{array}{l}130 \\
\text { With }\end{array}$ & $3(2-4)$ & 2 & 5 \\
$\begin{array}{l}\text { Re- } \\
\text { catherization }\end{array}$ & $20(13.3)$ & $5(4.75-6)$ & 4 & 7 \\
\hline
\end{tabular}

The minimum age of patient was 50 years and maximum age of patient on study is 90 years with mean age and standard deviation of $66.09 \pm 9.676$. Maximum patients $53(35 \%)$ were of the age group of $61-70$ years (Table 2).

\begin{tabular}{|ll|}
\hline \multicolumn{2}{|l|}{ Table 2. Age-wise distribution of participants. } \\
\hline Age Group (In Years) & $\mathbf{n}(\%)$ \\
$41-50$ & $6(4)$ \\
$51-60$ & $42(28)$ \\
$61-70$ & $53(35)$ \\
$71-80$ & $42(28)$ \\
$>81$ & $7(5)$ \\
Total & $150(100)$ \\
\hline
\end{tabular}

The maximum time for surgery was 80 minutes and minimum time for surgery was 30 minutes with mean duration of surgery with standard deviation of $52.91 \pm 11.224$ minutes. The maximum weight of resected prostate was 40 grams and minimum weight was 10 grams with mean weight of resected prostate 
was $20.37 \pm 6.381$ grams (Table 3 )

\begin{tabular}{|c|c|c|c|}
\hline Variables & Mean \pm S.D. & $\begin{array}{l}\text { M a } \times \text { i - } \\
\text { mum }\end{array}$ & Minimum \\
\hline $\begin{array}{l}\text { D u ration } \\
\text { of surgery } \\
\text { (minutes) }\end{array}$ & $52.91 \pm 11.224$ & 80 & 30 \\
\hline $\begin{array}{l}\text { Weight of } \\
\text { resected } \\
\text { Prostate } \\
\text { (grams) }\end{array}$ & $20.37 \pm 6.381$ & 40 & 10 \\
\hline
\end{tabular}

In total 150 patients, 20 (13.3\%) patients underwent re-catherization. Catheter was removed on 5th day to 7 th day after re-catherization, with mean and standard deviation of $4.4 \pm 1.086$ (Table 4).

\begin{tabular}{|ll|}
\hline Table 4. Re-catherization. \\
\hline Re-catherization & $\mathbf{n}(\%)$ \\
Yes & $20(14)$ \\
No & $130(86)$ \\
\hline
\end{tabular}

Re-catherization was done in 9 patients $(6 \%)$ due to clot and $11(7.3 \%)$ (Figure 1).

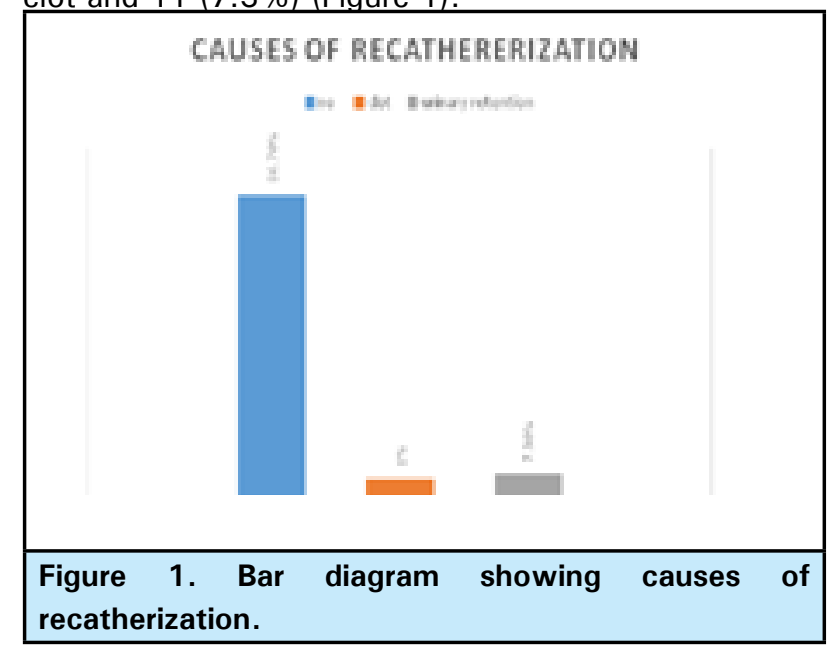

\section{DISCUSSION}

To reduce the length of hospital stay and costeffectiveness of the procedure, there is tendency to decrease the length of in-dwelling foley's catheter after TURP. Early catheter removal is been practiced in number of places to determine the safety and efficacy of this approach.3,6-11 Study reported that in certain patient. Early catheter did not increase morbidity rather it reduces the cost and hospital stay..$^{3,6-11}$

About one third of the total cost of TURP is represented by accommodation charges. ${ }^{9}$ The length of hospital stay for TURP decreased significantly between 1987 and 1995 from 10.6 to 6.1 days. ${ }^{12}$

The decreasing trend can be explained in basis of advancement of surgical technique and anaesthetic technique.

In this study, we have sucesfully removed the catheter on first POD in $130(86 \%)$ cases, where as $20(14 \%)$ cases recatherized due to above mentioned complications. The median duration of hospital stay in early removal of catheter was 3 (interquartile range 2-4) days which was similar to study done by Chalise et al. ${ }^{5}$

Many clinical trials have emphasized on early catheter removal after TURP, $6,11,13-18$ which helps in bed management, reduce cost and reduces the waiting list for TURP. Factors that influences the removal of catheter can be divided in three categories: Intrinsic patient factors, such as co-morbidities, urinary retention, hematuria, procedure specific factor such as resected prostate weight and intrinsic hospital factor and resourses. ${ }^{11,12}$

In one study it was found that duration of catheter removal related with resected prostatic weight, resected time and post -operative complication. we found that patient with no abnormalities, small prostatic size, less resection time and no peri operative complication were the candidate in whom we could remove catheter early and safely.

This study was done in a single institution with a limited sample size. Convenience sampling was done to enroll participants which might have introduced sampling error. Further multi-centric studies in a larger sample of patients which apply analytical study designs must be done in Nepal.

\section{CONCLUSIONS}

This study showed that the median duration of hospital stay after early removal of foley's catheter among patients undergoing transuretheral reseaction of prostate was similar to studies done in national and international settings.

\section{Conflict of Interest: None.}

\section{REFERENCES}

1. Barry MJ. Evaluation of symptoms and quality of life in men with benign prostatic hyperplasia. Urology. 2001 Dec 1;58(6):25-32. [PubMed | Full Text | DOI]
2. Gordon NSI. Costing Transurethral Resection of the Prostate and Diagnosis Related Group in Australia Compared with United States Costs. Aust N Z J Surg. 1994;64(2):95-8. 


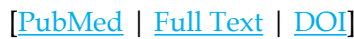

3. Cherrie RJ, Young RA, Cattolica EV. The safety of overnight hospitalization for transurethral prostatectomy: a prospective study of 200 patients. J Urol. 1997 Feb;157(2):531-3. [ | Full Text | DOI]

4. Mueller EJ, Zeidman EJ, Desmond PM, Thompson IM, Optenberg SA, Wasson J. Reduction of length of stay and cost of transurethral resection of the prostate by early catheter removal. Br J Urol. 1996 Dec;78(6):893-6. [ubMed | Full Text | DOI]

5. Chalise PR, Agrawal CS, Pandit RK. Reduction of length of hospital stay after transurethral resection of prostate by early catheter removal: a retrospective analysis. Nepal Med Coll J NMCJ. 2007 Jun;9(2):84-7. [․ㅏbMed]

6. Dodds L, Lawson PS, Crosthwaite AH, Wells GR. Early catheter removal: a prospective study of 100 consecutive patients undergoing transurethral resection of the prostate. Br J Urol. 1995 Jun;75(6):755-7. [ㄹued | Full Text | DOI]

7. Mamo GJ, Cohen SP. Early catheter removal vs. conventional practice in patients undergoing transurethral resection of prostate. Urology. 1991 Jun;37(6):519-22. [․ㅏbMed | Full Text $\mid \underline{\mathrm{DOI}}]$

8. Gordon NS. Catheter-free same day surgery transurethral resection of the prostate. J Urol. 1998 Nov;160(5):1709-12. [PubMed | Full Text $\mid \underline{\text { DOI] }}$

9. Mueller EJ, Zeidman EJ, Desmond PM, Thompson IM, Optenberg SA, Wasson J. Reduction of length of stay and cost of transurethral resection of the prostate by early catheter removal. Br J Urol. 1996 Dec;78(6):893-6. [PubMed | Full Text | DOI]

10. Gordon NS, Hadlow G, Knight E, Mohan P. Transurethral resection of the prostate: still the gold standard. Aust N Z J Surg. 1997 Jun;67(6):354-7. [PubMed | Full Text | DOI]
11. Feldstein MS, Benson NA. Early catheter removal and reduced length of hospital stay following transurethral prostatectomy: a retrospective analysis of 100 consecutive patients. J Urol. 1988 Sep;140(3):532-4. [라Med | Full Text I DOI]

12. Ansari MZ, MacIntyre CR, Ackland MJ, Chandraraj E, Hailey D. Predictors of length of stay for transurethral prostatectomy in Victoria. Aust N Z J Surg. 1998 Dec;68(12):837-43. [PubMed | Full Text | DOI]

13. Koh KB, Mac Dermott JP, Smith PH, Whelan P. Early catheter removal following transurethral prostatectomy--impact on length of hospital stay. Br J Urol. 1994 Jul;74(1):61-3. [Full $\underline{\text { Text }} \mid \underline{\text { DOI] }}$

14. Perera ND, Nandasena ACN. Early catheter removal after transurethral resection of the prostate. Ceylon Med J. 2002 Mar;47(1):11-2. [라Med | Full Text | DOI]

15. Valero Puerta JA, Sánchez González M, Medina Pérez M, Valpuesta Fernández I, Guerrero Guerra JL. [Reduction of hospital stay, because of the early removal of the bladder catheter in transurethral resection of the prostate]. Arch Esp Urol. 1998 May;51(4):327-30. Spanish. [PubMed]

16. Agrawal SK, Kumar AS. Early removal of catheter following transurethral resection of the prostate. Br J Urol. 1993 Dec;72(6):928-9. [PubMed | Full Text | DOI]

17. Aslan G, Celebi I, Arslan D, Esen AA. Early catheter removal following transurethral prostatectomy: overnight catheterization. Urol Int. 2002;68(2):105-8. [uuMed | Full Text | DOI]

18. Mottola A, Daniele G, Caselli B, Palminteri V. Early catheter removal following transurethral resection of the prostate. Minerva Urol E Nefrol Ital J Urol Nephrol. 1999 Jun;51(2):103-4. [ubMed | Full Text] 